\title{
Préface de Monsieur Hamad Kalkaba Malboum
}

\section{Président du Comité National Olympique et Sportif du Cameroun}

50 ans déjà...

50 ans jalonnés de succès éclatants et de grandes déceptions, que le Mouvement sportif s'est bâti, au fil des décennies, une réputation solide, s'inscrivant comme une réalité intangible dans la vie de notre pays.

50 ans aussi que beaucoup d'entre nous ont été des acteurs et des témoins de certaines étapes et nul n'est besoin de fouilles archéologiques pour retrouver cette histoire qui se construit sous nos yeux au quotidien.

Nous aurions pu organiser des Etats généraux ou un Forum sur le sport, le football en l'occurrence. Un de plus. Nous avons à dessein privilégié la réflexion, en nous fixant comme objectif de ratisser large, de retracer une sociohistoire du Mouvement sportif et de l'Olympisme dans notre pays à l'issue de ce Cinquantenaire. Nous portons résolument un regard rétrospectif et diagnostic afin de refonder à partir d'une démarche prospective, le devenir du sport et plus globalement, des Activités physiques au Cameroun.

Les thématiques, riches et variées, ont permis de camper notre rencontre sur une approche large et des sujets qui, en d'autres temps auraient fait chacun l'objet de plus d'un colloque. Elles ont tour à tour porté sur :

1. Les approches historiques et épistémologiques qui sont ouvertes aux réflexions sur les pratiques sportives au Cameroun, en particulier, leur genèse et les conditions de leur diffusion ; le poids et l'impact des influences coloniales ; et enfin les enjeux de la mondialisation examinés à l'aune des politiques juridiques et de la diplomatie sportive.

2. Le management des organisations sportives qui ont permis de revisiter les formes de structuration des clubs sportifs au Cameroun, les enjeux liés à la définition d'une politique fiscale en vue du financement du sport et enfin, les vertus des politiques locales en matière de promotion du sport.

3. Le droit du sport et la gestion des litiges sportifs, notamment leur règlement devant la Chambre de Conciliation et d'Arbitrage, leur perception par les acteurs du Mouvement sportif et enfin, leur traitement au niveau du prétoire international.

4. La démocratie sportive et l'unité nationale, de façon plus spécifique, la mise en questionnement de l'idée même de Nation avec comme corollaire les problématiques de la nationalité et le débat autour la démocratie sportive.

5. Le projet et la mise en ouvre de l'éducation olympique. Sont traités tour à tour, les rapports entre olympisme et droits de l'homme, les programmes d'éducation olympique et leur promotion dans les milieux scolaires et enfin, la création des Académies nationales olympiques et les Centres d'études olympiques en Afrique.

6. Enfin, des contributions et études diverses sur la reconversion des footballeurs professionnels camerounais, le passage de l'éducation du corps à une éducation 
physique et sportive, mais aussi, l'analyse des paramètres cardiologiques sportifs d'élite camerounais et les risques de mort subite. Et pour terminer, une célébration des grandes figures et des résultats marquants du sport camerounais.

Voilà mesdames et messieurs, chers sportifs et lecteurs de ces Actes du premier Symposium international de Yaoundé 2014, l'économie générale du travail que d'éminents universitaires et experts nationaux et internationaux ont bien voulu, au terme de deux jours d'intenses échanges, porter à votre connaissance. Je vous en souhaite une bonne lecture !

Hamad KALKABA MALBOUM Président du CNOSC 